\title{
Magnesium Deficiency in Palms ${ }^{1}$
}

Timothy K. Broschat ${ }^{2}$

\section{Symptoms}

Magnesium $(\mathrm{Mg})$-deficiency appears on the oldest leaves of palms as broad chlorotic (yellow) bands along the margins with the central portion of the leaves remaining distinctly green (Figures 1 and 2). In severe cases, only the rachis and adjacent portions of the leaflets remain green on the oldest leaves, but younger leaves show progressively wider bands of green along the centers of leaves. In Phoenix spp. (date palms), leaflet tips on the oldest leaves may be necrotic, but this necrosis is due to potassium $(\mathrm{K})$ deficiency superimposed on Mg-deficient leaves (Figures 3 and 4). In fan palms with deeply dissected leaves, the chlorosis may appear as broad yellow bands along the margins of individual leaflets (Figure 5). Magnesium deficiency is never fatal in palms.

\section{Cause}

Magnesium deficiency is caused by insufficient $\mathrm{Mg}$ in the soil. Magnesium is readily leached from sandy soils and other soils having little cation exchange capacity. High levels of $\mathrm{K}$ or calcium (Ca) in the soil can also induce or exacerbate $\mathrm{Mg}$ deficiencies.

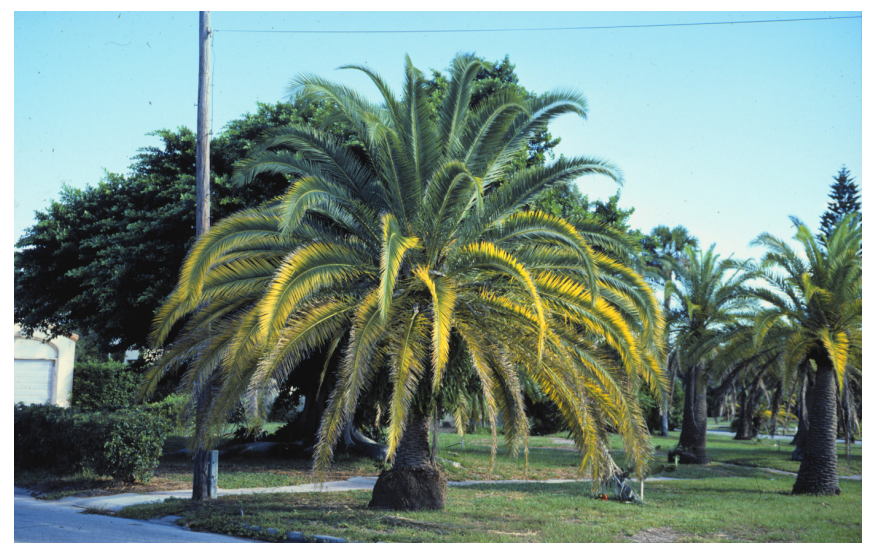

Figure 1. Magnesium deficiency on Phoenix canariensis (Canary Island date palm). Credits: T.K. Broschat

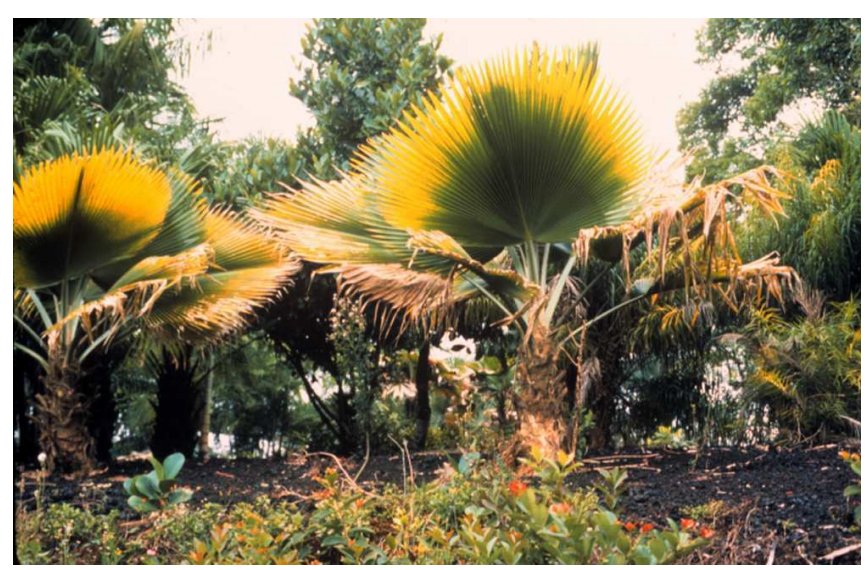

Figure 2. Magnesium deficiency on Pritchardia sp. Credits: T.K. Broschat

1. This document is ENH 1014, one of a series of the Environmental Horticulture Department, Florida Cooperative Extension Service, Institute of Food and Agricultural Sciences, University of Florida. Original publication date September 2005. Visit the EDIS Web Site at http://edis.ifas.ufl.edu.

2. Timothy K. Broschat is Professor, Environmental Horticulture Department, Fort Lauderdale Research and Education Center, Institute of Food and Agricultural Sciences, University of Florida, Fort Lauderdale, FL 33314 


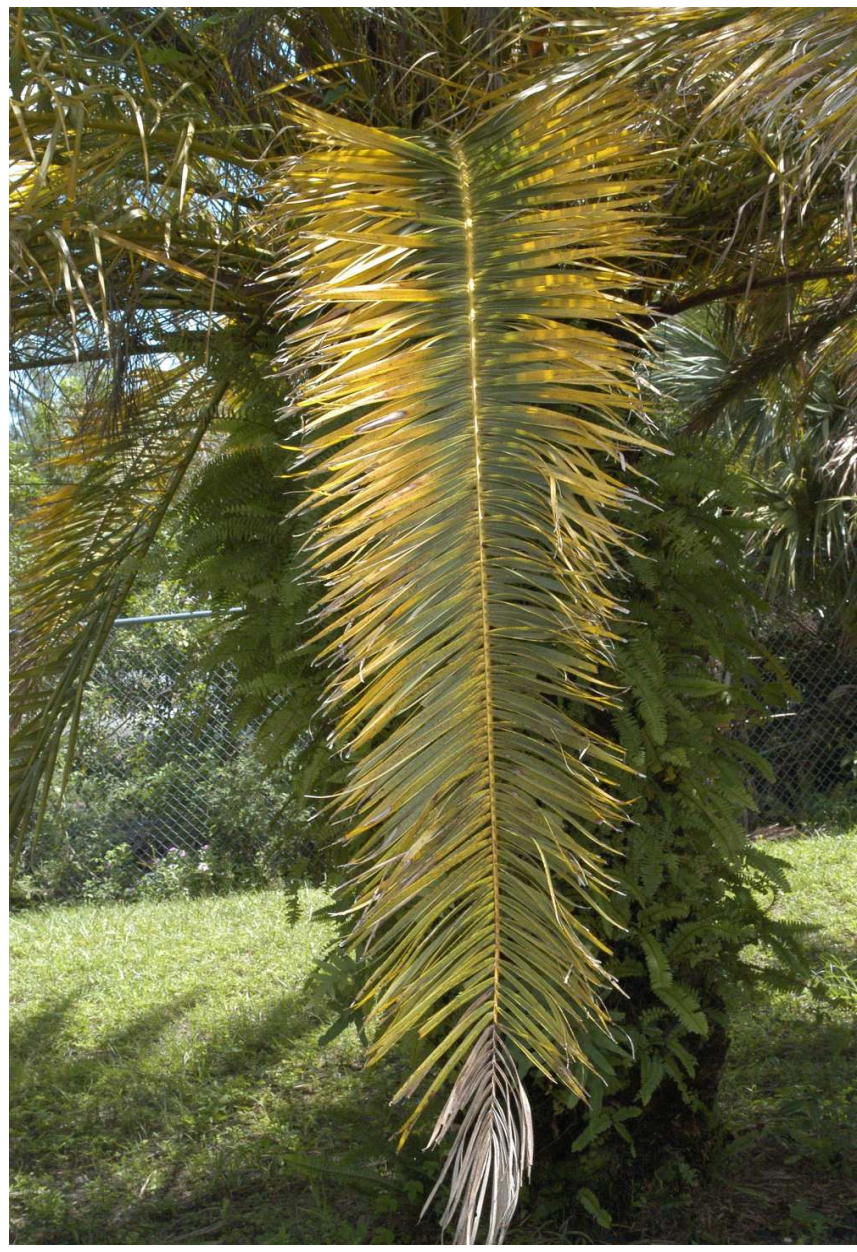

Figure 3. A single old leaf of Phoenix canariensis showing both $\mathrm{K}$ (tip) and $\mathrm{Mg}$ (base and middle) deficiency symptoms. Credits: T.K. Broschat

\section{Occurrence}

Magnesium deficiency is very common on highly leached soils in Florida, Hawaii, and other tropical areas. It can also occur in container-grown palms if dolomitic limestone has not been added to the substrate. Also, since palms may remain in a container for up to a year or longer, any added dolomite is usually exhausted after six months or so with $\mathrm{Mg}$ deficiency symptoms becoming visible as a result. Most species of palms are susceptible to $\mathrm{Mg}$ deficiency to some degree, but Phoenix canariensis is by far the most susceptible species to this disorder.

\section{Diagnostic Techniques}

Visual symptoms alone are usually sufficient to diagnose $\mathrm{Mg}$ deficiency although leaf nutrient analysis can also be helpful. Magnesium deficiency symptoms differ from those of K deficiency in that

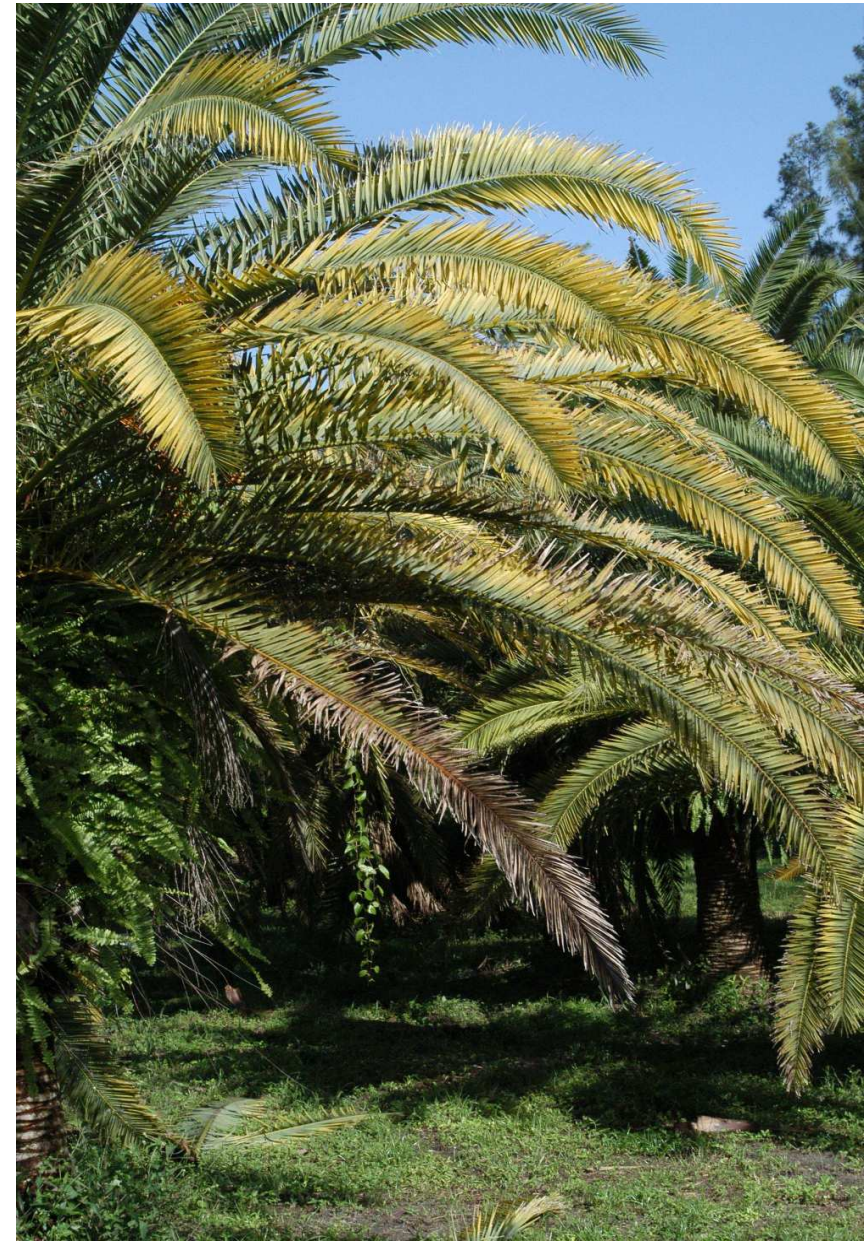

Figure 4. Phoenix canariensis showing both $\mathrm{K}$ (oldest leaves) and $\mathrm{Mg}$ (middle-aged leaves) deficiencies. Credits: T.K. Broschat

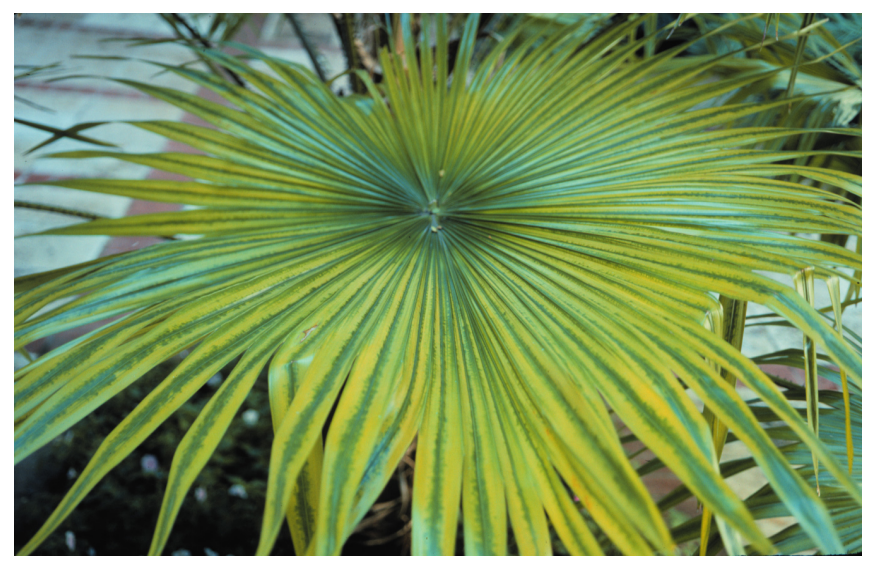

Figure 5. Magnesium-deficient older leaf of Livistona rotundifolia showing yellow borders around individual leaflets. Credits: T.K. Broschat

symptom severity of K-deficient leaves increases gradually from base to tip of the older leaf, whereas $\mathrm{Mg}$ deficiency symptoms are distributed uniformly from base to tip of the leaf. Discoloration of $\mathrm{K}$-deficient leaves is usually orange to bronze, 
shading gradually to green at the base of the leaf, whereas Mg-deficient leaves have distinctly green leaf centers and bright lemon yellow to orange (depending on the species) margins. There is never any necrosis associated with $\mathrm{Mg}$ deficiency, whereas leaflet necrosis is a common symptom on $\mathrm{K}$-deficient palms. It is possible for a palm to show symptoms of both deficiencies on a single leaf.

When sampling for leaf analysis, select 4 to 6 central leaflets from the youngest fully-expanded leaf. Soil analysis is not particularly useful for diagnosing palm nutrient deficiencies, since palm nutrient symptomology often bears little resemblance to soil nutrient profiles.

\section{Management}

Magnesium deficiency is difficult to correct once symptoms are present. In container-grown palms, It is best prevented by amending all container substrates with 12 to $15 \mathrm{lbs}$ of dolomite per cubic yard. For palms in landscapes and field nurseries in areas prone to $\mathrm{Mg}$ deficiency, $\mathrm{Mg}$ should be included in all fertilizers in a controlled-release form. On acid soils, dolomite or magnesium oxide can be used as controlled release $\mathrm{Mg}$ sources, but on neutral to alkaline soils prilled kieserite (the less soluble monohydrate form of magnesium sulfate) is an excellent controlled release source. Treatment of severely deficient palms can require one to two years or more and is accomplished by broadcasting magnesium sulfate (preferably in the less soluble prilled kieserite form) at rates of 2 to 5 pounds per tree 4 to 6 times per year to the area under the canopy. This treatment should be considered as a supplement to regular applications of a balanced $8-2-12+4 \mathrm{Mg}$ palm maintenance fertilizer. To reduce the potential for salt injury, $\mathrm{Mg}$ and maintenance fertilizer applications can be offset by six weeks. For mild to moderately severe $\mathrm{Mg}$ deficiencies, application of the $8-2-12+4 \mathrm{Mg}$ palm maintenance fertilizer at a rate of $1.5 \mathrm{lbs}$ per $100 \mathrm{sq} \mathrm{ft}$ of canopy area, bed area, or entire landscape area every three months should be adequate to treat and prevent $\mathrm{Mg}$ deficiencies. As with $\mathrm{K}$ deficiency, symptomatic leaves will never recover, but must be replaced by healthy new leaves. Foliar sprays with $\mathrm{Mg}$ fertilizers are generally ineffective in treating $\mathrm{Mg}$ deficiency since they supply very small amounts of $\mathrm{Mg}$ relative to the amount required by palms. See also ENH1009.

\section{Selected References}

Broschat, T.K. 1984. Nutrient deficiency symptoms in five species of palms grown as foliage plants. Principes 28:6-14.

Broschat, T.K. 1997. Release rates of controlled release and soluble magnesium fertilizers. HortTechnology 7:58-60.

Dickey, R.D. 1977. Nutritional deficiencies of woody ornamental plants used in Florida landscapes. Univ. Fla. Agric. Exp. Sta. Bull. 791. 